\title{
The epidemiology of herpes simplex Types 1 and 2 infection of the genital tract in Edinburgh 1978-1991
}

\author{
J D C Ross, I W Smith, R A Elton
}

\begin{abstract}
Introduction-The changing epidemiology of genital herpes in Edinburgh is described in relation to herpes simplex virus (HSV) Type 1 and herpes simplex virus Type 2 infection over a period of 14 years.

Methods-2018 episodes of genital herpes in 1794 patients over a 14 year period were assessed. Data on age, sex, sexual orientation, geographical origin and herpes antibodies were also analysed. Results-The proportion of cases that were HSV Type 1 increased over the period from approximately $20 \%$ to over 40\%. Type 1 infection is more common in the young, in women and as a primary infection.

Conclusions-HSV Type 1 is of increasing importance as a cause of genital herpes in our population. This may reflect changes in sexual attitudes and practises over the past decade.
\end{abstract}

(Genitourin Med 1993;69:381-383)

\section{Introduction}

Genital herpes is the commonest ulcerating sexually transmitted disease seen in the UK and is caused by infection with either herpes simplex virus (HSV) Type 1 or herpes simplex virus Type $2 .{ }^{1}$ The clinical importance of HSV infection lies in both its ability to produce painful, disabling and recurrent disease in addition to its potential role as a co-factor in the acquisition, transmission and possibly progression of HIV disease. ${ }^{2}$ We describe the changing epidemiology of genital herpes in Edinburgh with respect to viral type over a period of 14 years.

\section{Methods}

All patients presenting to the Department of Genitourinary Medicine at Edinburgh Royal Infirmary, Edinburgh between January 1978 and December 1991 with a diagnosis of genital herpes simplex infection were included in the analysis. The diagnosis of genital herpes was made on the basis of clinical appearance. Laboratory confirmation and typing was carried out by immunofluorescent staining of infected cells from Hef cell monolayers. Initially an "in-house" immunofluorescent stain was used ${ }^{3}$ until the Syva direct test became available. Serological studies were done on paired sera, collected at a $2-4$ week interval, by complement fixation using the 1:4 dilution of HSV Type 1 antigen as described previously. ${ }^{4}$ This test will detect primary HSV Type 1 or Type 2 infections but does not distinguish between them. Geographical site of acquisition of infection, age, sexual orientation, sex and frequency of re-attendance were also analysed with respect to HSV type. The associations betwen gonorrhoea, chlamydia and genital warts with HSV type were investigated.

Statistical analysis was performed using Mann Whitney, Chi square and Fisher's exact test on SPSS and Epiinfo software.

\section{Results}

Patients ( $n=1794)$ with 2018 episodes of infection presented with genital herpes over the study period. Of these 1961 isolates were typed in 1744 patients. Demographic data were available on the following numbers of patients: geographical location in 1547 patients, age and sex in 1794 patients, sexual orientation in 1684 patients. Paired sera were available for 909 patients -414 had primary infection and 495 had non primary infection.

The number of cases of genital herpes presenting annually to the clinic increased over the study period from 84 (1978) to 159 (1991). There was, however, a dip in the prevalence of $\mathrm{HSV}$ in the mid-1980s before a return to the upward trend. The ratio of HSV Type 1 to HSV Type 2 infection increased significantly in the mid 1980s $(p<0.001)$ and by the end of the decade HSV Type 1 accounted for over $40 \%$ of genital herpes genital infections (fig 1). Type 1 infections were almost twice as common in women $(39 \%)$ as in men $(22 \%)$ by the end of the study period (fig 2) but there was no significant difference between the number of male and female patients (M:911, F:883). Female patients presented with $\mathrm{HSV}$ infection at an earlier age (median 24 years) than male patients (median 27 years-p $<0.001$ ). No association between homosexual or heterosexual intercourse and viral type was demonstrated although homosexual men with HSV infection were older than heterosexuals $(\mathrm{p}<0.05)$.

The geographical origin of primary perpetic infection was more often foreign (outwith the UK) for Type 2 infections (21/188 $-11 \%)$ than Type 1 infections (10/192$5 \%)-p<0.05$. Infections in women tended to originate more often from Edinburgh itself

21 May 1992
} 


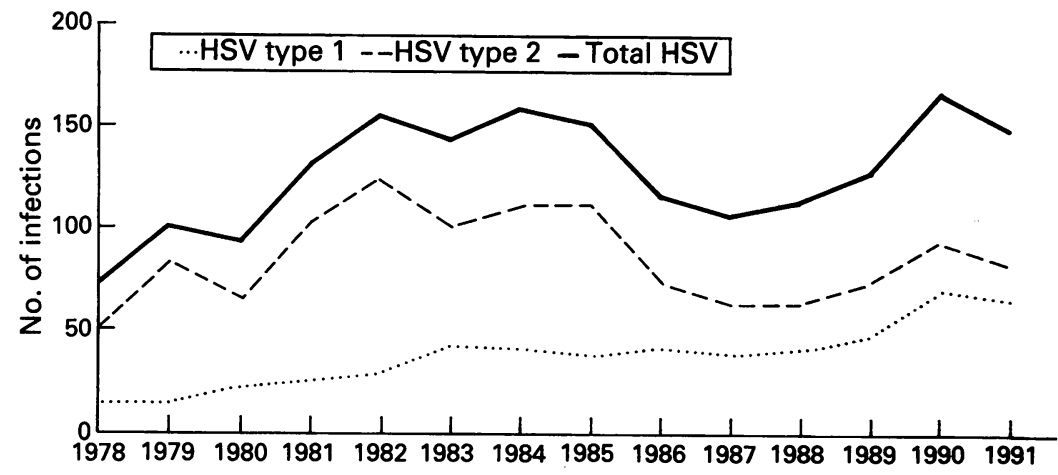

Figure 1 Prevalence of genital herpes 1978-91.

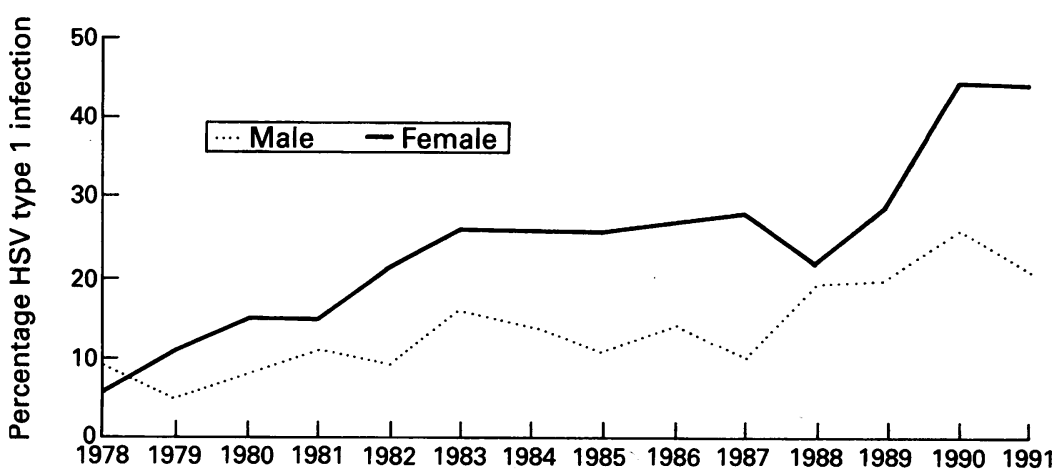

Figure 2 Sex distribution of HSV Type 1 infection.

(161/224-72\%) compared with those in men $(101 / 163-62 \%)-\mathrm{p}<0.01$.

A diagnosis of primary genital herpes confirmed by serology was strongly correlated with HSV Type 1 infection (204/279 (73\%) cf. $201 / 608(33 \%)$ for HSV Type 2$\mathrm{p}<0.001$, nine untyped). Primary infection was commoner in younger patients $(p<0.001)$ and in women $(241 / 414(58 \%)$ in primary infection cf. $244 / 495(49 \%)$ in non primary infection- $-p<0.01$ ) (table).

Five patients with primary HSV infection due to HSV Type 2 were also infected with Neisseria gonorrhoeae at the time of diagnosis whilst no primary infection with HSV Type 1 was associated with gonococcal infection$p<0.05$. There was no significant difference in concomitant infections with either chlamydia or genital warts between HSV 1 and HSV 2 infections.

\section{Conclusions}

The annual incidence of genital herpes infection almost doubled over the 14 year study period from 84 . to 159 but the greatest

Table The relationship between age with sex and primary infections

\begin{tabular}{lcc}
\hline $\begin{array}{l}\text { Age group } \\
\text { (years) }\end{array}$ & $\begin{array}{l}\text { No primary } \\
\text { infections (\% age } \\
\text { of age cohort) }\end{array}$ & $\begin{array}{l}\text { No female } \\
\text { infections (\% age } \\
\text { of age cohort) }\end{array}$ \\
\hline Under 20 & $54(68 \%)$ & $64(81 \%)$ \\
$20-24$ & $173(53 \%)$ & $194(60 \%)$ \\
$25-29$ & $109(44 \%)$ & $129(52 \%)$ \\
Over 29 & $78(30 \%)$ & $98(38 \%)$ \\
\hline
\end{tabular}

increase occurred in HSV Type 1 infections which increased fourfold in the same time period. The increase in genital herpes over the past decade has been noted in other parts of the UK, ${ }^{5-7}$ but the reasons for HSV Type 1 becoming a more common cause of genital herpes remain unclear. Possible explanations include changes in sexual behaviour of the population and/or changes in viral pathogenicity. Changes in sexual practises are difficult to measure but an increase in oral sex is likely to have occurred within the study period as this was widely advocated as a form of "safe sex" to reduce the transmission of the human immunodeficiency virus (HIV). The reduction in clinic attendances for $\mathrm{HSV}$ observed in the mid-1980s may also be related to safer sexual behaviour secondary to the perceived threat of HIV infection. The associated reduction in the incidence of gonorrhoea ${ }^{8}$ may also have been secondary to increased condom usage but condoms are probably seldom used during oral sex. In one study $^{9}$ of patients with first episode genital herpes $13 \%$ of women and $7 \%$ of men had HSV isolated from the pharynx with $36 \%$ giving a history of oral sex and $7 \%$ of cases of genital herpes caused by HSV Type 1 . The pharyngeal carriage rate of HSV Type 1 will obviously vary between populations and within populations over time. ${ }^{10}$ In addition the acquisition of HSV Type 1 is now less common in early childhood ${ }^{11}$ leaving young sexually active adults at greater risk of infection since they lack protective antibody.

We found that female patients were twice as likely to present with an HSV Type 1 infection and this association between HSV Type 1 and women has been described previously. ${ }^{67}$ The higher occurrence in women may relate to reporting differences as the more severe clinical infection seen in women ${ }^{912}$ is more likely to present to a clinic. However, the approximately equal numbers of men and women in the study is against reporting bias of this sort. Additionally although recurrent herpes is more common with Type 2 infection ${ }^{6}$ viral subtype is not correlated with the severity of initial infection. ${ }^{1}$

As has also been demonstrated by others ${ }^{79}$ we found that women present at an earlier age with genital herpes than men. Primary genital herpes confirmed by serology was significantly more likely to be Type 1 in origin.

An association between $\mathrm{HSV}$ and gonorrhoea has been noted by Wentworth et al ${ }^{13}$ but the increased incidence of concurrent gonorrhoea in HSV Type 2 infections is of interest and may reflect the differing routes of acquisition of the two viral subtypes. It also supports the concept that the rise in HSV Type 1 infection is secondary to an increase in fellatio and cunnilingus with their associated lower risk of acquiring cervical or urethral gonorrhoea.

In conclusion there has been a rapid increase in the incidence of HSV Type 1 genital herpes in Edinburgh over the past decade which may reflect changes in sexual practice 
within the community. Young female patients are particularly likely to have Type 1 as compared with Type 2 infections and this is of relevance when counselling patients with regard to their subsequent risk of recurrence.

1 Corey L. Genital Herpes. In: Holmes KK, Mardh P, Sparling PF, et al, eds. Sexually Transmitted Diseases. 2nd Ed. New York. McGraw-Hill.

2 Holmberg SM, Stewart JA, Geiber R, et al. Prior herpes simplex virus type 2 infection as a risk factor for $\mathrm{HIV}$ infection. $\mathcal{\text { sim }}$ iMA 1988;259:1048-50

3 Peutherer JF, Smith IW, Robertson DHH. Genital infection with herpes simplex virus type 1 . $f$ Infect 1982;4 33-5.

4 Smith IW, Peutherer JF, MacCallam FO. The incidence of Herpesvirus hominis antibody in the population. f Hygiene Cambridge 1967;65:395-408.

5 Sexually Transmitted Diseases in Britain: 1985. London. Communicable Diseases Surveillance Centre. CDS 88/04.
6 Lavery HA, Connolly JH, Russell JD. Incidence of herpes genitalis in Northern Ireland in 1973-83 and herpes simplex type 1 and 2 isolated in 1982-84. Genitourin simplex type 1 and

7 Scoular A, Leask B, Carrington D. Changing trends in genital herpes due to Herpes Simplex virus type 1 in Glasgow, 1985-88 (letter). Genitourin Med 1990 66:226.

8 Ross JDC, Scott GR. Seasonal variation in gonorrhoea. Eur $\mathcal{F}$ Epidemiol 1992;8:252-5.

9 Corey L, Adams HG, Brown ZA, Holmes KK. Genital herpes simplex virus infections: Clinical manifestations, course, and complications. Ann Int Med 1983.98: 958-72.

10 Hatherley LT, Hayes K, Jack I. Herpes virus in an Obstetric hospital II: Asymptomatic viral excretion in Obstetric hospital II: Asymptomatic viral

11 Wolontis S, Roizman B. Infection with Herpes Simplex virus 1 and 2. N Eng $\mathcal{f}$ Med 1973;289:781-9.

12 Mindel A, Coker DM, Faherty A, Williams P. Recurren genital herpes: clinical and virological features in me and women. Genitourin Med 1988;64:103-6.

13 Wentworth BB, Bonine P, Holmes KK, Alexander ER Isolation of viruses, bacteria and other organisms from venereal disease clinic patients: Methodology and problems associated with multiple isolations. Health $\mathrm{Lab} S \mathrm{Si}$ 1973;75:10-5. 